\title{
NMDA Receptors in Layer 4 Spiny Stellate Cells of the Mouse Barrel Cortex Contain the NR2C Subunit
}

\author{
Alexander M. Binshtok, ${ }^{1}$ Ilya A. Fleidervish, ${ }^{1}$ Rolf Sprengel, ${ }^{2}$ and Michael J. Gutnick ${ }^{1}$ \\ ${ }^{1}$ Koret School of Veterinary Medicine, The Hebrew University of Jerusalem, Rehovot 76100, Israel, and 2Department of Molecular Neurobiology, Max- \\ Planck Institute for Medical Research, D-69120 Heidelberg, Germany
}

In layer 4 of the somatosensory cortex, the glutamatergic synapses that interconnect spiny stellate (SpS) neurons, which are the major targets of thalamocortical input, differ from most other neocortical excitatory synapses in that they have an extremely large NMDA receptor (NMDAR)-mediated component that is relatively insensitive to voltage-dependent $\mathrm{Mg}^{2+}$ blockade. We now report that this unique feature of the NMDA response reflects the distinctive subunit composition of the underlying receptors. We studied NMDARmediated miniature EPSCs (mEPSCs) and NMDA channel currents in tangential brain slices of mouse barrel cortex, which exclusively contain layer 4. NMDAR-mediated mEPSCs in SpS neurons were prominent at negative membrane potentials, and NMDA channels in outside-out patches excised from the somata of the same neurons had relatively low conductance and reduced susceptibility to $\mathrm{Mg}^{2+}$ block. These are characteristic features of heteromeric NMDAR assemblies that contain the NR2C subunit. Some patches also contained NMDA channels with higher conductance and a greater sensitivity to $\mathrm{Mg}^{2+}$. In the neocortex of transgenic mice in which a $\beta$-galactosidase (lacZ) indicator gene was controlled by the NR2C promoter, the lacZ indicator was densely expressed in layer 4 . In current-clamp recordings, blockade of NMDARs caused hyperpolarization and an increase in apparent input resistance. Our data demonstrate that the SpS neurons of layer 4 functionally express NR2C subunits; this is the likely explanation for their ability to generate large NMDAR-mediated EPSPs that are effective at resting potential, without previous depolarization.

Key words: somatosensory cortex; tangential slice; excitatory postsynaptic current; NMDA channels; patch clamp; spiny stellate neuron

\section{Introduction}

The voltage-dependent $\mathrm{Mg}^{2+}$ block of NMDA receptors (NMDARs) helps to confer on them a crucial role in plasticity and memory (Constantine-Paton et al., 1990; Bliss and Collingridge, 1993), because it limits the amount of current they pass at resting membrane potential and thereby imposes a requirement for previous conditioning depolarization to attain full activation. However, we (Fleidervish et al., 1998) and others (Feldmeyer et al., 1999) have shown that in spiny stellate (SpS) neurons in layer 4 of rodent somatosensory ("barrel") cortex, NMDAR activity is relatively high even at resting potential. Two explanations have been offered to explain the large contribution of NMDARs to synaptic events at less depolarized potentials: Feldmeyer et al. (1999), who reported a strong NMDARmediated component to the EPSPs elicited in paired recordings from layer $4 \mathrm{SpS}$ cells of rat barrel cortex, attributed this to an increased density of "classical" NMDARs in postsynaptic spines. In contrast, we (Fleidervish et al., 1998) proposed that because $\mathrm{Mg}^{2+}$ sensitivity of the NMDAR is governed by the NR2 subunit of the heteromeric channel (Monyer et al., 1992; Nakanishi,

Received April 7, 2005; revised Nov. 22, 2005; accepted Nov. 23, 2005.

This work was supported by a grant from the Israel Science Foundation, administered by the Israel Academy of Sciences and Humanities.

Correspondence should be addressed to Michael J. Gutnick, Koret School of Veterinary Medicine, The Hebrew University of Jerusalem, P.0. Box 12, Rehovot 76100, Israel. E-mail: gutnick@agri.huji.ac.il.

DOI:10.1523/JNEUROSCI.4409-05.2006

Copyright $\odot 2006$ Society for Neuroscience $\quad$ 0270-6474/06/260708-08\$15.00/0
1992), the prevalence of NMDAR-mediated EPSPs that we observed at $-70 \mathrm{mV}$ in $\mathrm{SpS}$ neurons of the mouse barrel cortex reflects a distinctive subunit composition. We suggested that many of the intracortical excitatory synapses onto these cells contain the NR2C subunit, which has been shown to confer a decreased sensitivity to $\mathrm{Mg}^{2+}$ blockade (Monyer et al., 1992, 1994; Farrant et al., 1994; Momiyama et al., 1996).

In our previous study (Fleidervish et al., 1998), we introduced a new tangential brain slice preparation, which almost entirely consists of layer 4 of the barrel cortex and in which the SpS neuron is the dominant cell type. In the present study, we correlate the characteristics of miniature EPSCs (mEPSCs) as manifested in whole-cell recordings with the properties of somatic NMDA channels, as revealed in outside-out patch-clamp recordings. We demonstrate that in addition to the highly voltage-dependent NMDARs in which one or more NR1 subunits are combined with NR2A and/or NR2B subunits, layer $4 \mathrm{SpS}$ cells also express NMDARs with lower conductance levels and reduced sensitivity to $\mathrm{Mg}^{2+}$ block, typical of heteromeres that contain the NR2C or NR2D subunit (Cull-Candy and Leszkiewicz, 2004). Furthermore, we demonstrate that SpS neurons express the NR2C subunit, as evidenced by dense staining of layer 4 in sections from transgenic mice in which the NR2C promoter region has been linked to an indicator $[\beta$-galactosidase $(\mathrm{lac} Z)]$ gene. We also present evidence for the specific posttranslational targeting of the different NMDAR subtypes to different individual synapses. Finally, we show that in these neurons, tonic activation of NMDARs may contribute to the resting membrane potential. 


\section{Materials and Methods}

Neocortical slices were prepared from CD-1 mice using established procedures (Fleidervish et al., 1996, 1998). Unless otherwise specified, all mice were aged postnatal day 20 (P20) to P24. Animals were deeply anesthetized with Nembutal ( $40 \mathrm{mg} / \mathrm{kg}$ ) and decapitated, and the brains were quickly removed and placed in cold, oxygenated artificial CSF (aCSF) containing the following (in $\mathrm{mm}$ ): $124 \mathrm{NaCl}, 3 \mathrm{KCl}, 2 \mathrm{CaCl}_{2}, 2$ $\mathrm{MgSO}_{4}, 1.25 \mathrm{NaH}_{2} \mathrm{PO}_{4}, 26 \mathrm{NaHCO}_{3}, 10$ glucose ( $\mathrm{pH} 7.3$ when bubbled with $\left.95 \% \mathrm{O}_{2}-5 \% \mathrm{CO}_{2}\right)$. Slices $(400 \mu \mathrm{m})$ were cut from the barrel area of the neocortex, either in the coronal plane or in a plane tangential to the pial surface, as described previously in detail (Fleidervish et al., 1998). Slices were placed for at least $1 \mathrm{~h}$ in a holding chamber filled with oxygenated aCSF at room temperature before they were transferred to the recording chamber.

Whole-cell voltage-clamp and outside-out recordings were made either blindly or under IR-DIC microscopic control, as described previously (Fleidervish et al., 1996). The recording pipettes (2-4 M $\Omega$ ) were coated with Sylgard (Dow Corning, Midland, MI) and filled with intracellular solution containing the following (in $\mathrm{mM}$ ): $135 \mathrm{CsCl}, 2 \mathrm{MgCl}_{2}, 1$ $\mathrm{CaCl}_{2}, 11$ EGTA, 10 HEPES (pH 7.2 with $\mathrm{CsOH}$ ). Care was taken to maintain membrane access resistance as low as possible (usually 3-4 M $\Omega$ and always $<10 \mathrm{M} \Omega$ ); in whole-cell configuration, series resistance was $80 \%$ compensated using the built-in circuitry of an Axopatch-1D amplifier (Molecular Devices, Foster City, CA). Bicuculline methiodide (BMI; $10 \mu \mathrm{M}$ ) and 6,7-dinitroquinoxaline-2,3-dione (DNQX; 20-40 $\mu \mathrm{M}$ ) were routinely added to the bath to block $\mathrm{GABA}_{\mathrm{A}}$ receptor $\left(\mathrm{GABA}_{\mathrm{A}}-\mathrm{R}\right)$ and AMPA receptor (AMPAR-R)-mediated conductances, respectively. For channel recordings, the bath contained strychnine $(1 \mu \mathrm{M})$ and TTX (1 $\mu \mathrm{M})$. All records were analog filtered at $2 \mathrm{kHz}(-3 \mathrm{~dB} ; 4$-pole Bessel) and digitized at $5-10 \mathrm{kHz}$.

Whole-cell current-clamp recordings from the soma of layer $4 \mathrm{SpS}$ neurons were obtained using an Axopatch 200B amplifier (Molecular Devices) in fast current-clamp mode. When the pipette solution contained (in $\mathrm{mM}$ ) $135 \mathrm{~K}$ gluconate, $6 \mathrm{KCl}, 2 \mathrm{MgCl}_{2}$, and $10 \mathrm{HEPES}$ (potassium salt), $\mathrm{pH} 7.25$, the resting membrane potential was $-75.8 \pm 1.2 \mathrm{mV}$ $(n=56)$, apparent input resistance was $382 \pm 32 \mathrm{M} \Omega(n=58)$, and membrane time constant was $45.1 \pm 9.8(n=54)$. Command protocols were generated and data were acquired on-line with a Digidata 1320A interface (Molecular Devices). Data were low-pass filtered at $10 \mathrm{kHz}(-3$ $\mathrm{dB}, 4$-pole Bessel filter) and digitized at $20 \mathrm{kHz}$.

For analysis of single-channel currents, the events were examined at potentials between -70 and $+60 \mathrm{mV}$, and their amplitudes were measured (pClamp 9; Molecular Devices). Channel openings were identified by eye (by two independent observers) and measured with cursors. Only events at voltages far enough from the reversal potential for the signalto-noise ratio to permit clear identification of openings and longer than three times the digitization interval were accepted for analysis. Mean single-channel currents were estimated from multiple Gaussian fits to the amplitude distributions (Origin 6.0; Microcal, Northampton, MA). Mean amplitudes were then plotted against voltage, and the data were fitted by linear regression to give slope-conductance and reversal potential. The rates of transition between main and subconductance states were measured in patches that possessed only one NMDA channel or a homogenous channel population (Wyllie et al., 1996). At least 1000 well resolved consecutive transitions per patch were analyzed (pClamp 9).

For analysis of mEPSCs and spontaneous EPSCs (sEPSCs) (in the presence and absence of TTX, respectively), events were collected and aligned at the half-amplitude time of their rising edge using a templatebased search paradigm (pClamp 9; Molecular Devices) with a relatively low threshold to detect as many events as possible. Only events that were confirmed by direct visual inspection were included. The time intervals between the neighboring events were used to calculate the mean instantaneous EPSC frequency. For this purpose, the occurrence of an EPSC was defined as the time at its peak. Individual EPSC amplitudes were calculated by subtracting mean membrane current over a $5 \mathrm{~ms}$ period immediately before the rising phase of an EPSC from the current at the EPSC peak. The EPSC rise time was determined as the interval from 10 to $90 \%$ of the peak amplitude. Decay time constants were obtained from single exponential fits to the decay phase of individual, nonoverlapping events detected with 100- to 120-ms-long template window. In each case, between 200 and 500 events per cell were analyzed. Additional statistical analysis used median values of peak amplitude, rise time, and decay time constant. Unless otherwise noted, values are given as mean \pm SD. A Student's $t$ test was performed to determine whether differences in parameters under different experimental conditions were significant. For amplitude and kinetic characteristics of EPSCs under various experimental conditions, see supplemental Table 1 (available at www.jneurosci.org as supplemental material).

Transgenic mice that regulate the expression of the $\beta$-galactosidase indicator gene (lacZ) by a fragment of the NR2C promoter were produced as described previously (Suchanek et al., 1997). A plasmid containing $1.0 \mathrm{~kb}$ downstream of the $400 \mathrm{bp}$ NR2C promoter fragment inserted into lacZ indicator vector pnlacF (Mercer et al., 1991) was injected into the pronucleus (Kimura et al., 1992). Positive mice were identified by PCR of genomic DNA isolated from the tail biopsies (Brusa et al., 1995) using primers S38 (CAC CAC GGC TTG GTT CCC CTC) and lacM13. To determine lacZ expression, horizontal sections of the whole mouse brains were fixed in $2 \%$ paraformaldehyde for $1 \mathrm{~h}$, rinsed several times in PBS, incubated for $24 \mathrm{~h}$ in 5 -bromo-4-chloro-3-indolyl- $\beta$-D-

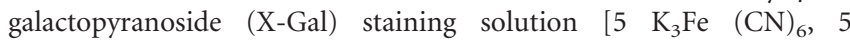
$\mathrm{K}_{4} \mathrm{Fe}(\mathrm{CN})_{6}, 2 \mathrm{MgCl}_{2}, 1.2 \mathrm{mg} / \mathrm{ml} \mathrm{X-Gal} \mathrm{in} \mathrm{PBS]}$, and studied and photographed under a microscope. Nissl-stained sections (1 $\mu \mathrm{m}$ thick) through the edge of tangential layer 4 slices that had been used previously for electrophysiological experiments were prepared according to standard procedures (Carson, 1990).

\section{Results}

NMDAR-mediated sEPSCs at negative membrane potentials appear in layer 4 neurons after the first postnatal week

Whole-cell recordings from $\mathrm{SpS}$ neurons were made in tangential slices, which primarily contain layer 4 barrels (Fleidervish et al., 1998). In slices from animals older than P5, the typical barrel organization was clearly visualized at low magnification, and higher magnification IR-DIC video microscopy revealed individual small neurons, the somatic and dendritic morphology of which was clearly distinguished from the neurons of other cortical layers (Fig. 1A). We refer to all of these neurons as SpS cells, although some may be "star pyramids." These were indistinguishable from $\mathrm{SpS}$ neurons in our experiments, because the somata of the two cell types are quite similar, and the apical dendrite is not apparent in a tangential slice (White and Rock, 1980). We demonstrated previously (Fleidervish et al., 1998) that mature SpS cells differ from other neocortical neurons in that they generate NMDAR-mediated synaptic currents at membrane potentials near rest. Thus, in animals older than P8, DNQX-resistant, spontaneous synaptic events were prominent at $-70 \mathrm{mV}$ in all layer 4 SpS neurons $(n>100)$, despite the presence of $2 \mathrm{mM} \mathrm{Mg}^{2+}$ (Fig. $1 C, D$ ). These were APV sensitive and were present with or without a $\mathrm{GABA}_{\mathrm{A}}$ blocker in the bath (Fig. 1D). In slices from animals younger than P8, NMDAR-mediated postsynaptic currents were never seen at $-70 \mathrm{mV}$, although they were prominent at $+40 \mathrm{mV}(n=12)$ (Fig. $1 B)$.

\section{NMDAR-mediated mEPSCs and NMDA channels in layer 4 neurons}

Our strategy for characterizing NMDARs was to first record whole-cell properties of mEPSCs in the presence of TTX. Then, the pipette was slowly withdrawn and an excised, outside-out patch was positioned facing the opening of a puffer pipette that contained glutamate and glycine in aCSF (Fig. $1 E$ ). In two of three patches, a brief pressure application resulted in a longlasting barrage of channel activity, which was completely and reversibly blocked by APV. Because there are no glutamatergic 
synapses on the somata of these cells (White and Rock, 1980), we assume that these channels were extrasynaptic NMDARs.

Figure $2 \mathrm{~A}$ illustrates the DNQXresistant, APV-sensitive, slowly decaying $\left(\tau=20.45 \pm 3.69 \mathrm{~ms}\right.$ at $\left.21-23^{\circ} \mathrm{C} ; n=15\right)$ mEPSCs that were prominent at $-70 \mathrm{mV}$ in all layer $4 \mathrm{SpS}$ neurons, the NMDAR channel properties of which were subsequently examined. Because the recordings were made in the presence of TTX $(1 \mu \mathrm{M})$, each event was generated by current passing through NMDARs at individual glutamatergic synapses in response to spontaneous quantal transmitter release. NMDAR-mediated synaptic activity was never recorded at $-70 \mathrm{mV}$ in layer 5 neurons under the same experimental conditions $(n=18)$ (Fig. $2 B)$, although it was present in all cells at positive membrane potentials (data not shown).

The traces in the middle panels of Figure 2, $A$ and $B$, show recordings of NMDA channels in patches from the layer 4 and 5 neurons, respectively, illustrated in the top panels. In each case, two distinct conductance levels could be distinguished with clear transition between them. Linear regression analysis of the channel currentvoltage relationship revealed that in the layer 4 neuron, the high-conductance state had a slope conductance of $30 \mathrm{pS}$, whereas the subconductance state was $19 \mathrm{pS}$ (Fig. $2 \mathrm{~A}$, bottom). In contrast, in the layer 5 neuron, the main conductance level was $51 \mathrm{pS}$ and the subconductance level was 41 pS (Fig. 2B, bottom). Similar 51/41 pS channels were the only NMDAR type recorded in all layer 5 neurons; these are the characteristic conductance states previously reported for receptors that contain the NR2A or the NR2B subunit (CullCandy and Leszkiewicz, 2004). Patches from 11 of the 15 layer 4 SpS cells contained only $30 / 19$ pS channels; these are the characteristic conductance states reported previously for receptors containing the NR2C or NR2D subunit (Cull-Candy and Leszkiewicz, 2004). Patches from the remaining $4 \mathrm{SpS}$ cells contained both channel types (Fig. 3A). A detailed analysis of the rates of transition between main and subconductance states in patches from layer 4 cells, which possessed a homogenous population of 30/19 pS channels, revealed that the number of transitions from the $30 \mathrm{pS}$ state to the $19 \mathrm{pS}$ state was approximately the same $(51.6 \pm 1.5 \%)$ as the number of transitions from the $19 \mathrm{pS}$ state to the $30 \mathrm{pS}$ state $(49.5 \pm 1.2 \%)$. This symmetry is typical of channels containing NR2C subunit but not the NR2D subunit (Wyllie et al., 1996).

\section{Voltage dependence of NMDA channels}

To characterize the voltage dependence of NMDA channels of layer $4 \mathrm{SpS}$ cells, we applied voltage ramps $(+40$ to $-70 \mathrm{mV})$ to outside-out patches, which contained both high- and lowconductance channel types (Fig. $3 B$ ). Two hundred traces con-
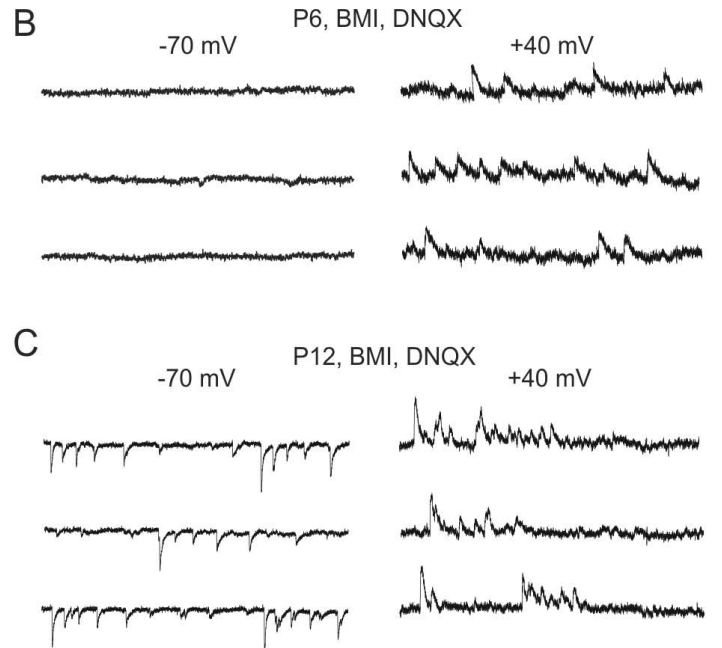

$10 \underline{\mu m}$

Wash in APV

Wash out APV

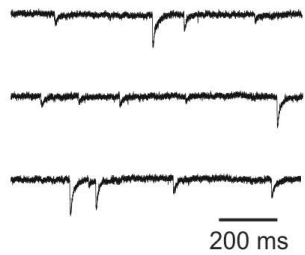

Wash out APV

Wash in APV

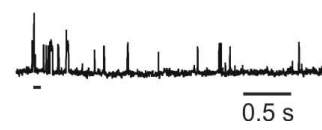

| $1 \mathrm{pA}$

$5 \mathrm{~s}$

Figure 1. In layer 4 of the mouse barrel cortex, NMDAR-mediated EPSCs at voltages near the resting potential appear after the first postnatal week. $\boldsymbol{A}$, Top, Unstained $400-\mu \mathrm{m}$-thick tangential slice from a P20 mouse, containing layer 4 of the posteromedial magnification. $\boldsymbol{B}, \mathrm{At}$ P6, whole-cell recording from a layer $4 \mathrm{SpS}$ cell does not show any NMDAR-mediated activity at $-70 \mathrm{mV}$ 列

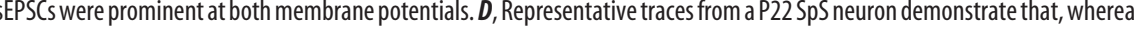
inhibitory transmission was intact (no BMI was added into extracellular solution), APV-sensitive NMDAR-mediated sEPSCs were

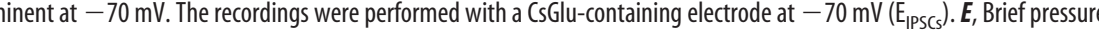
ong-lasting barrage of channel activity, which was completely and reversibly blocked by $50 \mu \mathrm{M} A P V$. In this and all subsequent figures, aCSF contained $10 \mu \mathrm{m} \mathrm{BMI}$ and $20 \mu \mathrm{m}$ DNQX.

taining only one kind of opening were separated (Fig. 3B, left), and the currents were averaged and plotted as a function of membrane potential (Fig. 3B, right). In the presence of physiological concentration of $\mathrm{Mg}^{2+}$, both types of channels displayed a significant inward rectification, whereas $I-V$ relationships were linear (data not shown; $n=3$ ) in the absence of $\mathrm{Mg}^{2+}$. The susceptibility of the $30 / 19 \mathrm{pS}$ channel to $\mathrm{Mg}^{2+}$ block, however, was significantly lower than that of the $51 / 41 \mathrm{pS}$ channel (Fig. $3 B$, right). Assuming that the different subunit combinations that make up these extrasynaptic NMDARs are also present in the synapses, neurons that express the low-conductance channels would be expected to display significant NMDA-mediated synaptic activity even at voltages around resting potential.

\section{NR2C subunit expression in layer 4 neurons}

The attributes of 30/19 pS extrasynaptic NMDA channels in layer 4 neurons, including symmetrical transition rates between main and subconductive states and reduced sensitivity to $\mathrm{Mg}^{2+}$ block, 
A

\section{LAYER 4}

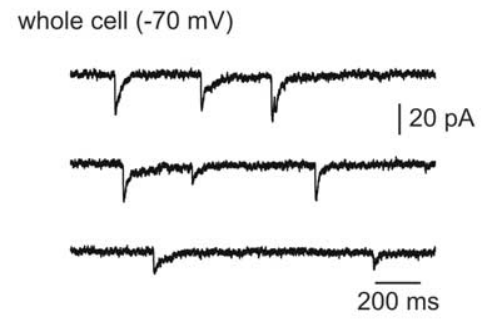

outside-out patch

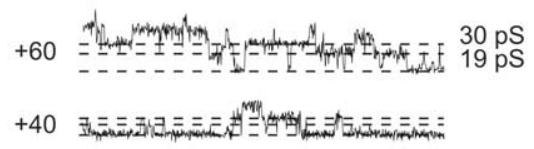

0

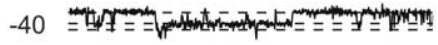

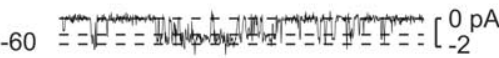

$$
\overline{20 \mathrm{~ms}}
$$

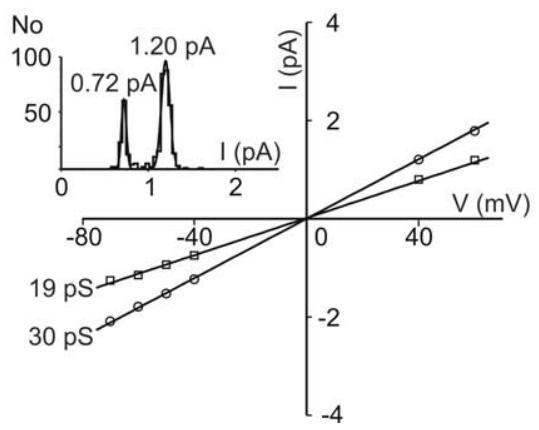

B

\section{LAYER 5}

whole cell $(-70 \mathrm{mV})$
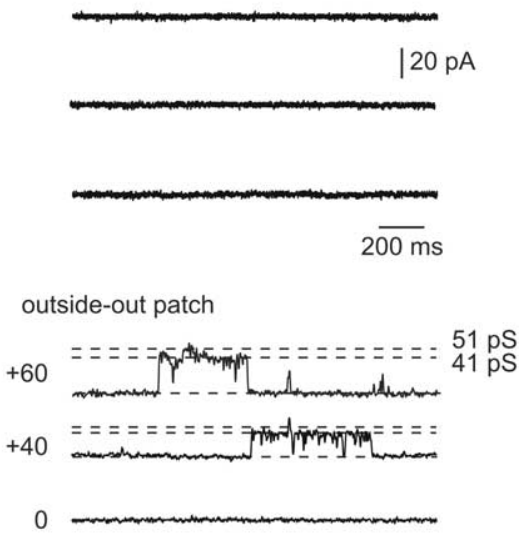

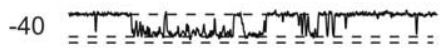

$-60 \begin{aligned} & - \\ & z=z-z=z\end{aligned}$

$20 \mathrm{~ms}$

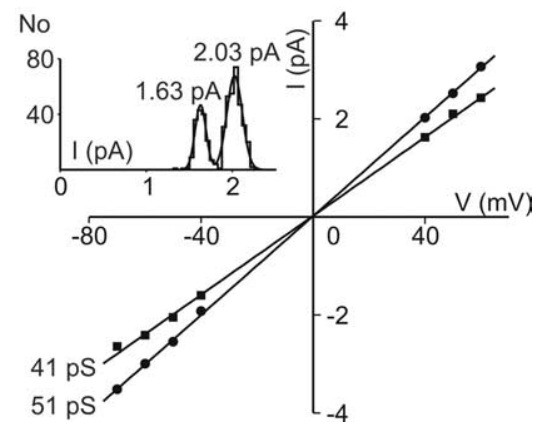

Figure 2. Conductance properties of NMDA channels in layer 4 SpS neurons differ from those in layer 5 pyramidal neurons. $A$, Whole-cell and outside-out recordings from a layer 4 cell. Top, Prolonged NMDAR-mediated mEPSCs in a neuron held at $-70 \mathrm{mV}$. Middle, Channel recordings from an outside-out patch excised from the same neuron and held at different voltages during exposure to a combination of $0.2 \mathrm{~mm}$ glutamate and $0.1 \mathrm{~mm}$ glycine. Dashed lines indicate the two conductance states and the closed state. Bottom, Current-voltage relationship obtained by measuring the amplitudes of 200-1000 well resolved openings for each membrane potential. The data are drawn from the patch shown in the middle panel. Linear regression analysis reveals slope conductances of 19 and $30 \mathrm{pS}$ and a reversal potential of $0.2 \mathrm{mV}$. Inset, Amplitude distribution and fit with the sum of two Gaussians at $+40 \mathrm{mV}$. $\boldsymbol{B}$, Top, Under the same experimental conditions, the was no NMDAR-mediated activity in a layer 5 neuron at $-70 \mathrm{mV}$. Middle, NMDA channel currents elicited by glutamate/glycine application to the outside-out patch, which was excised from the same neuron. Bottom, Current-voltage relationship and linear regression analysis provided estimated slope conductances of 41 and $51 \mathrm{pS}$ and a reversal potential of $0.1 \mathrm{mV}$. Inset, Amplitude distribution and fit with the sum of two Gaussians at $+40 \mathrm{mV}$.

closely resembles the properties of recombinant (Monyer et al., 1992, 1994; Wyllie et al., 1996) and native (Watanabe et al., 1992; Farrant et al., 1994; Momiyama et al., 1996; Misra et al., 2000) NMDARs assembled from the NR1 and NR2C subunits. To clarify whether NR2C subunit expression may indeed explain the distinctive properties of NMDARs in these neurons, in a parallel study, we used the transgenic mice that express the $\beta$-galactosidase indicator gene (lacZ) controlled by the NR2C promoter (Suchanek et al., 1997). Monitoring of the $\beta$-galactosidase expression by conversion of the chromogenic substrate X-Gal from yellow to blue revealed the NR2C promoter activation in cerebellum and olfactory bulb, where the NR2C mRNA (Watanabe et al., 1992; Monyer et al., 1994; Sun et al., 2000) and functional 31/19 pS channels (Farrant et al., 1994) have been reported previously. In the neocortex, the $\beta$-galactosidase expression was very sparse in layer 5 and a little denser in layers 2-3 and 6 . However, it formed a clear, dense band throughout layer 4 (Fig. $4 A$ ). At higher magnification, the morphological appearance of the somata of lacZ-stained neurons (Fig. 4B, left) was similar to that of Nissl-stained layer $4 \mathrm{SpS}$ cells (Fig. $4 B$, right), with lacZ intensely staining the entire cytoplasm. The cell densities in layer 4 were not obviously different with the two stains, indicating that virtually all SpS cells had stained for lacZ. In contrast, layer 5 pyramidal cells did not stain for lacZ (Fig. $4 B$, center). Although numbers of neurons per unit volume do differ from layer to layer, with layer 4 being the most dense (DeFelipe et al., 2002), this variation cannot account for the conspicuous laminar difference in lacZ staining. The higher cell density in layer 4 reflects, in part, the smaller somatic volume, and because lacZ stained the entire cytoplasm if the same proportion of cells in other layers were to be stained, the amount of stained cytoplasm would not be that different, and the laminar variation would be far less obvious.

\section{Distribution of NR2 subunits among synapses}

Together, the above evidence strongly supports the hypothesis that the distinctive voltage dependence of NMDAmediated synaptic activity in layer $4 \mathrm{SpS}$ neurons reflects the presence of NMDARs that contain NR2C (although NR2D cannot be rigorously ruled out; see Discussion). Because our channel recordings showed that these cells also express higherconductance NMDARs, we sought to gain information about the distribution of the different subunits among the synapses on a given neuron by comparing the frequencies of NMDAR-mediated mEPSCs at -70 and $+40 \mathrm{mV}$. Assuming that vesicular release of glutamate is not directly influenced by postsynaptic membrane potential, an increase in the frequency of mEPSCs after depolarization indicates the presence of synapses in which the NMDARs pass current at positive voltages but undergo almost complete $\mathrm{Mg}^{2+}$ blockade at negative membrane potentials. Conversely, an unchanged mEPSC frequency at the two voltages would indicate that the high- and low-conductance subunits are colocalized in the same synapses.

The cumulative histograms in Figure $5 \mathrm{~A}$ demonstrate that the mean interval between detectable NMDAR-mediated mEPSCs recorded from a representative layer 4 neuron was far longer at $-70 \mathrm{mV}(0.40 \mathrm{~s})$ than at $+40 \mathrm{mV}(0.14 \mathrm{~s})$ in the presence of $2 \mathrm{~mm}$ $\mathrm{Mg}^{2+}$, and that the difference disappeared when $\mathrm{Mg}^{2+}$ was removed from the bath solution ( 0.16 vs $0.15 \mathrm{~s}$, respectively). The bar graphs of Figure $5 B$ show pooled results from 12 neurons 
recorded at the two voltages before and after removal of $\mathrm{Mg}^{2+}$. In the presence of $\mathrm{Mg}^{2+}$, mEPSC frequency rose from $2.4 \pm$ $0.1 \mathrm{~Hz}$ at $-70 \mathrm{mV}$ to $6.8 \pm 0.8 \mathrm{~Hz}$ at +40 $\mathrm{mV}(p<0.001$; paired $t$ test $)$, and the difference between two potentials became insignificant after washout of $\mathrm{Mg}^{2+}$. We conclude that although SpS cells do express NR1/NR2C receptors, they have a population of glutamatergic synapses in which the NR2C subunit is absent.

To check for the presence of synapses in which all NMDARs contain the NR2C subunit, we strove to block all NMDARmediated activity at resting membrane potential. In this series of experiments, slices were incubated for $3 \mathrm{~h}$ in aCSF that contained the open-channel NMDAR blocker (+)-5-methyl-10,11-dihydro-5H-

dibenzo [a,d] cyclohepten-5,10-imine maleate (MK-801; $40 \mu \mathrm{M})$; TTX was added to prevent spontaneous depolarizations. After washout of the blocker, mEPSCs were completely abolished at $-70 \mathrm{mV}$ but not at $+40 \mathrm{mV}$. However, as shown in Figure $5 C$, the frequency of mEPSCs at +40 $\mathrm{mV}(4.1 \pm 0.6 \mathrm{~Hz} ; n=5)$ was significantly lower than in neurons in control slices that had been incubated in TTX-containing aCSF without MK-801 $(6.2 \pm 1.3 \mathrm{~Hz} ; n=$ $5)$. We reasoned that the decreased frequency at positive potentials reflected blockade of the NMDARs that could open at resting potential and had therefore been blocked. NMDARs can recover very slowly from MK-801 blockade, and the time course of recovery is agonist and voltage dependent (Huettner and Bean, 1988). Thus, we may have underestimated the effect. However, because events were sampled within $3 \mathrm{~min}$ of the voltage step to $+40 \mathrm{mV}$, and the exposure of receptors to glutamate during $\mathrm{mEPSC}$ generation is sporadic, such relief was most likely minimal. In a parallel series of recordings from layer 5 neurons, mEPSC frequencies at $+40 \mathrm{mV}$ were not different for neurons in preincubated $(n=5)$ and control $(n=5)$ slices. These results indicate the presence of a mechanism for segregation of distinctive subtypes of NMDARs to different synapses.

\section{Effect of tonic NMDAR activity at resting potential}

Sah et al. (1989) reported that ambient glutamate can have a tonic effect on neuronal excitability despite the voltage dependence of NMDARs. Having determined that layer $4 \mathrm{SpS}$ neurons express both synaptic and extrasynaptic NMDARs that can pass current at potentials near rest, we reasoned that ambient glutamate in an active slice would influence the subthreshold membrane properties. To test this, we performed current-clamp recordings in slices that were bathed in aCSF that contained $5 \mathrm{mM} \mathrm{K}^{+}$and $1.2 \mathrm{~mm}$ $\mathrm{Ca}^{2+}$ to favor spontaneous firing and glutamate release (Sanchez-Vives and McCormick, 2000). The recording pipettes contained $N$-ethyl bromide quaternary salt (QX-314) to prevent spiking and to block persistent $\mathrm{Na}^{+}$current in the neuron under study. Resting potentials under these conditions were $-65 \pm 3$ $\mathrm{mV}(n=6)$, which is considerably more depolarized than the $-76 \mathrm{mV}$ recorded in usual aCSF (Fleidervish et al., 1998), and quite close to the potential reported for in vivo recordings from
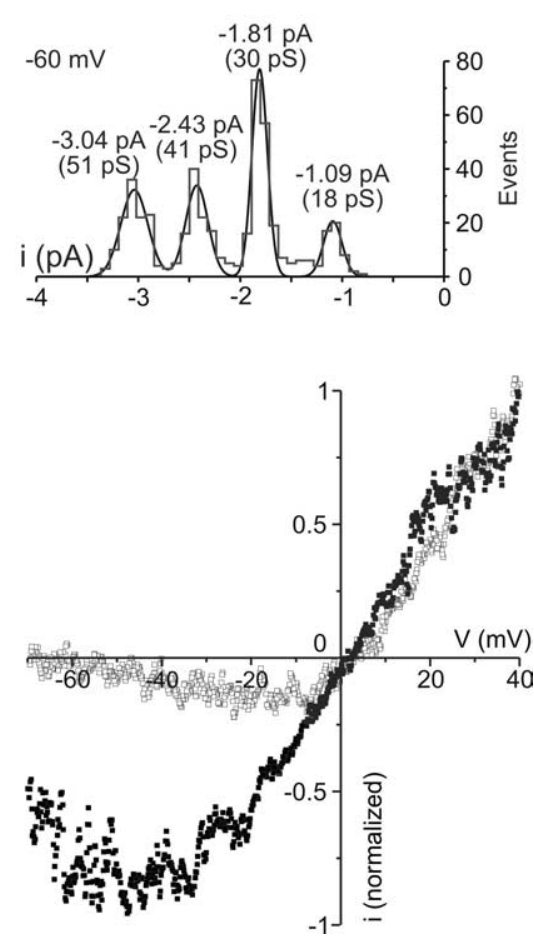

$-70 \mathrm{mV}$$$
51 / 41 \mathrm{pS}
$$

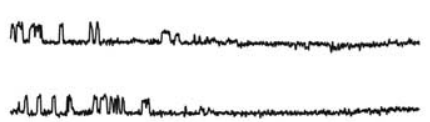

$30 / 19 \mathrm{pS}$

Figure 3. Low-conductance NMDA channels in SpS neurons are less susceptible to $\mathrm{Mg}^{2+}$ blockade at negative membrane tials. $A$, Left, Channel records from an outside-out patch that contains both high-and low-conductance type channels. Right, an instantaneous current-voltage relationship (right). Note that the inward current through 30/19 pS channel is significantly larger (closed squares) than that through 51/41 pS channel (open squares) over a wide voltage range ( -10 to $-70 \mathrm{mV})$.

layer 4 neurons (Zhu and Connors, 1999). Addition of APV to the bath caused membrane hyperpolarization by $1-6 \mathrm{mV}(n=6)$. Thus, the neuron illustrated in Figure 6 hyperpolarized from -64 to $-70 \mathrm{mV}$, with a concomitant increase in apparent input resistance by $26 \%$.

\section{Discussion}

These data strongly indicate that the molecular mechanism underlying the distinct voltage sensitivity of NMDAR-mediated synaptic activity that characterizes layer $4 \mathrm{SpS}$ neurons entails expression of the NR2C subunit. Channel recordings reveal the expression of an NMDAR, the conductance and subconductance states ( $30 \mathrm{pS}$ and $19 \mathrm{pS}$ ) of which indicate a subunit combination that includes either NR2C or NR2D. In addition to NR1 and NR2, the NMDA channel conductance would also be influenced by the presence of an NR3 subunit (Das et al., 1998). However, the conductance levels of NR3-containing heteromeres are very different from those recorded here (Green and Gibb, 2001; Sasaki et al., 2002). Moreover, expression of NR3 protein in mouse cortical neurons peaks during the first week of life and then falls steadily, such that none is present by P20 (Sasaki et al., 2002) when the vast majority of our channel recordings were made.

That the channels we recorded contained the NR2C subunit is suggested by the observed symmetrical transitions from one conductance state to the other (Wyllie et al., 1996). It is confirmed by the finding that lacZ staining linked to the NR2C promoter formed a clear, dark band specifically in layer 4 , where it appeared in SpS cells. Sparse staining was also seen in other neocortical layers and, indeed, pharmacological evidence for the presence of functional NR2C- or NR2D-containing NMDARs has been re- 


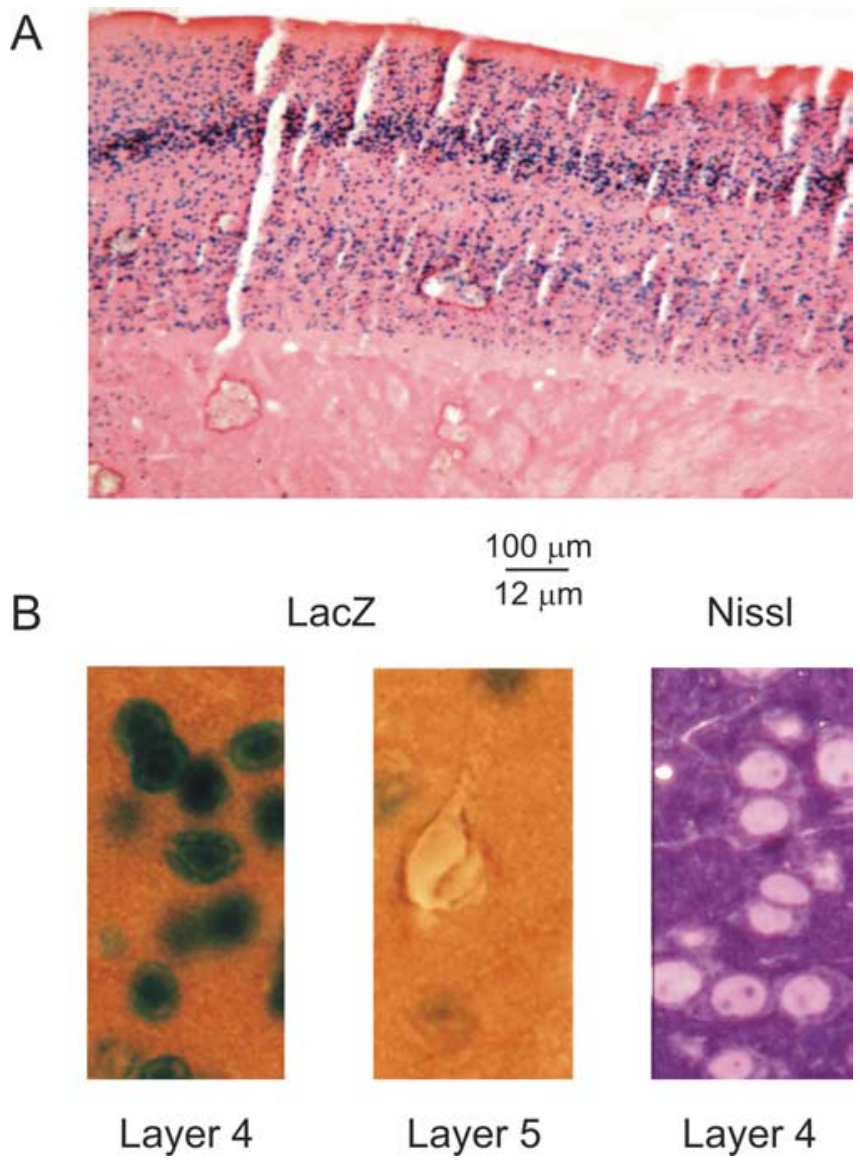

Figure 4. Layer 4 neurons express the NR2C subunit of NMDAR. $A$, Horizontal section from the $S 1$ region of a transgenic mouse that expressed a lacZ indicator gene controlled by the NR2C promoter region. Note that lacZ expression, while sparsely scattered throughout the layers, is particularly dense in layer 4. B, Somatic morphology of lacZ-expressing neurons in layer 4 (left) is very similar to that of SpS neurons, as shown in a $1 \mu \mathrm{m}$ Nissl-stained section from a layer 4 brain slice previously used in a physiological experiment (right). lacZ is not expressed in layer 5 pyramidal neurons (middle).

ported in pyramidal neurons, although NR2A/B activity is far more dominant in these neurons (Kumar and Huguenard, 2003). Using in situ hybridization, Munoz et al. (1999) demonstrated a high expression of the NR2C subunit, which is restricted to layer 4 in area $3 \mathrm{~b}$ of monkey sensory-motor cortex.

The SpS cells also express an NMDAR with 51 and $41 \mathrm{pS}$ conductance states. These were the characteristics of all of the NMDA channels we recorded in patches from layer 5 pyramidal cells, and they indicate the presence of NR2A or NR2B subunits (Cull-Candy and Leszkiewicz, 2004).

It is important to note that our patches were all from extrasynaptic somatic membrane. Although they do confirm the expression of the protein by the cell, the channel recordings do not necessarily indicate the NMDAR subunits present in the synapses themselves, because these are all located on dendritic spines of layer 4 SpS neurons (White and Rock, 1980). Clark et al. (1997) characterized the synaptic channels in cerebellar granule cells, which are quite small, by recording synaptically activated channel activity in whole-cell configuration. Although the SpS cells are also very compact, the cable properties of the spines preclude this approach in these neurons. Thus, we cannot rigorously exclude the possibility that the SpS neurons also express NR2D, and that the presence of NMDAR-mediated EPSCs at hyperpolarized potentials actually is attributable to the presence of this subunit in
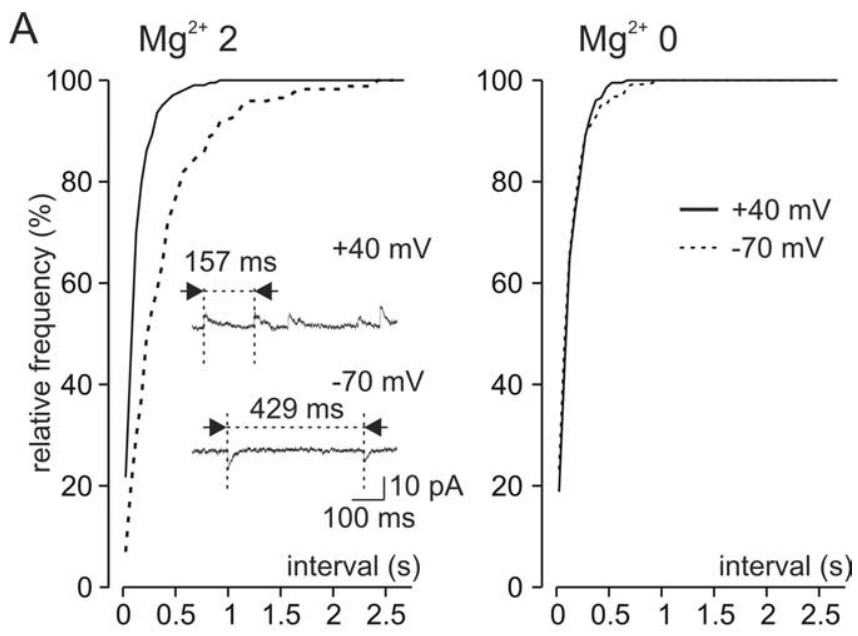

B
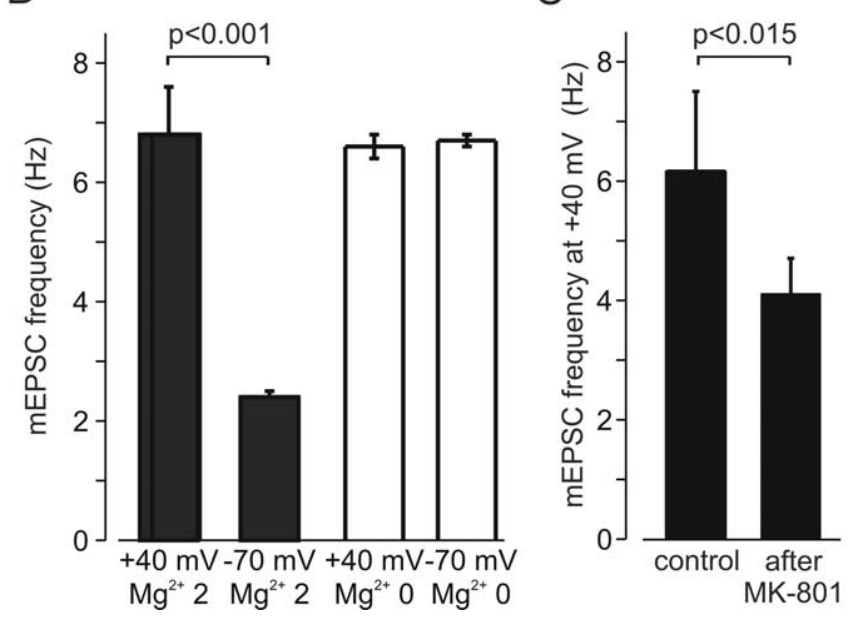

Figure 5. Nonhomogeneous distribution of subtypes of NMDARs among individual synapses, as revealed by voltage dependence of $\operatorname{mEPSC}$. $\boldsymbol{A}$, Left, Cumulative distribution of time intervals between NMDAR-mediated mEPSCs recorded at $-70 \mathrm{mV}$ (dashed line) and $+40 \mathrm{mV}$ (continuous line) in the presence of $2 \mathrm{~mm} \mathrm{Mg}^{2+}$. Note that at $-70 \mathrm{mV}$, the intervals between detectable mEPSCs are significantly longer. Inset, Sample current traces at -70 and $+40 \mathrm{mV}$. Right, After $\mathrm{Mg}^{2+}$ wash out, mEPSC frequency at $-70 \mathrm{mV}$ increased, such that cumulative distribution of intervals between NMDAR-mediated mEPSCs at the two potentials did not differ. $\boldsymbol{B}$, The voltage dependence of frequency of NMDAR-mediated mEPSCs. The bar graphs show mean frequency at -70 and $+40 \mathrm{mV}$ recorded in the presence of $2 \mathrm{~mm} \mathrm{Mg}^{2+}$ (filled bars) and in $\mathrm{Mg}^{2+}$-free solution (open bars). $C$, In a different set of experiments, after $3 \mathrm{~h}$ of incubation in the presence of the open-channel NMDAR blocker MK-801 (40 $\mu \mathrm{M})$, mEPSCs were completely blocked at $-70 \mathrm{mV}$ (data not shown), and $\mathrm{mEPSC}$ frequency at $+40 \mathrm{mV}$ was significantly decreased.

the synapses. However, because the cells are shown to functionally express NR2C, and none of the extrasynaptic channels showed the hallmark characteristics of NR2D-containing receptors, we consider it likely that the unique voltage dependence of NMDA-mediated mEPSCs in the layer 4 neurons indeed reflects the presence of NR2C subunits in some of the glutamatergic synapses.

We previously showed that different types of NMDARmediated EPSCs could be generated in the same SpS neuron. Thus, in the presence of an AMPA receptor blocker, minimal stimulation at one site near a cell could evoke an EPSC that was prominent at resting potential, whereas stimulation at another site near the same neuron elicited an EPSC that was only evident after depolarization. We took this as evidence that NR2C and 
NR2A (or NR2B) subunits are segregated to different synapses. This interpretation is confirmed here by the finding that when $\mathrm{Mg}^{2+}$ is present, mEPSC frequency is much higher at more depolarized postsynaptic potentials, indicating that many synapses exclusively contain NR2A/2B. Furthermore, after incubation with MK-801 to irreversibly block all NMDARs that open at the resting potential, no mEPSCs were present at $-70 \mathrm{mV}$, and the $\mathrm{mEPSC}$ frequency at positive potentials was significantly reduced, indicating the presence of synapses that exclusively contain NR2C. We cannot exclude the possibility that there are also synapses in which both types of NMDAR colocalize. Nevertheless, the data do indicate that in layer 4 cells, posttranslational trafficking of NMDARs is subunit specific, as has been shown previously for NMDARs (Hoffmann et al., 2000; Kumar and Huguenard, 2003), for AMPA receptors (Beattie et al., 2000; Lin et al., 2000) and for $\mathrm{GABA}_{\mathrm{A}}$ receptors (Nusser et al., 1998).

Anatomical evidence indicates that $\sim 15 \%$ of the excitatory synapses onto a layer $4 \mathrm{SpS}$ cell are with thalamocortical fibers (White and Rock, 1980), whereas the remaining input is from intracortical sources almost exclusively in the same barrel (Schubert et al., 2003). Gil and Amitai (1996) showed that the NMDAR-mediated component of the EPSP elicited by thalamocortical axons only becomes apparent during postsynaptic depolarization. Intracortical synaptic activity, in contrast, is heterogeneous. Recordings from pairs of SpS neurons show that they are connected by up to five synapses, and that the NMDAR-mediated component of EPSPs between them can be quite sizable at resting potential and in the presence of an AMPAR blocker (Fleidervish et al., 1998; Feldmeyer et al., 1999). In view of the large number of synapses, we find with NR2A/B characteristics it is likely that not all the synaptic contacts between SpS cells have the same subunit composition. This is consistent with data from recent $\mathrm{Ca}^{2+}$ imaging experiments (Nevian and Sakmann, 2004), which showed that local $\mathrm{Ca}^{2+}$ influx into spines of SpS neurons during EPSPs is through NMDARs, and that its dependence on AMPAR activation varies greatly from spine to spine. Thus, $\mathrm{Ca}^{2+}$ influx was completely abolished by an AMPAR blocker in only 3 of 11 spines examined [Nevian and Sakmann (2004), their Fig. 8]. Viewed in the light of our data, this observed heterogeneity probably reflects variation in the subunit composition of NMDARs in intracortical synapses.

Because the physiological manifestations of NMDAR subunit composition are so great, the appearance of NR2C after the first week of life must have significant functional consequences. In the brain, one of the most important functions of the NMDAR is to mediate plastic changes in synaptic efficacy. It is interesting that the potent NMDA-dependent long-term potentiation (Crair and Malenka, 1995) and long-term depression (Feldman et al., 1998), which apparently play an essential role in layer 4 circuit development and require conditioning depolarization of the $\mathrm{SpS}$ cells, can no longer be evoked after the first postnatal week, when the NR2C-containing receptors first appear. At later times, plasticity involving SpS neurons is not NMDA dependent. Thus, recording from pairs of SpS neurons in rat barrel cortex during the third postnatal week, Egger et al. (1999) described long-lasting plastic changes in synaptic efficacy that were dependent on metabotropic glutamate receptors but not NMDARs.

As in the cerebellar cortex (Cull-Candy and Leszkiewicz, 2004) and also in layer 4 of the neocortex, the role of the NR2Ccontaining NMDARs in local circuit function remains unclear. One cardinal feature of the NMDAR is its long decay time constant (McBain and Mayer, 1994). The presence of a subunit assembly, the weak sensitivity of which to $\mathrm{Mg}^{2+}$ block is readily relieved by slight membrane depolarization, means that very slow EPSPs are generated and may sum at voltages near the resting potential. If the main source of this input is other $\mathrm{SpS}$ cells, circulation of these activities within a barrel could produce a nearly tonic background of inward current onto which phasic thalamocortical inputs impinge. Indeed, we show that when excitability of the layer 4 network is elevated, sustained NMDAR activation directly contributes to the membrane potential and resting conductance of an SpS neuron. It is important to note that extrasynaptic as well as synaptic NMDARs probably contribute to this effect. Activation of NMDARs near resting potential may also result in local $\mathrm{Ca}^{2+}$ influx and consequent activation of $\mathrm{Ca}^{2+}$ dependent processes (Isaacson and Murphy, 2001).

\section{References}

Beattie EC, Carroll RC, Yu X, Morishita W, Yasuda H, von Zastrow M, Malenka RC (2000) Regulation of AMPA receptor endocytosis by a signaling mechanism shared with LTD. Nat Neurosci 3:1291-1300.

Bliss TV, Collingridge GL (1993) A synaptic model of memory: long-term potentiation in the hippocampus. Nature 361:31-39.

Brusa R, Zimmermann F, Koh DS, Feldmeyer D, Gass P, Seeburg PH, Sprengel R (1995) Early-onset epilepsy and postnatal lethality associated with an editing-deficient GluR-B allele in mice. Science 270:1677-1680.

Carson F (1990) Histotechnology: a self-instructional text, Ed 1. Chicago: ASCP.

Clark BA, Farrant M, Cull-Candy SG (1997) A direct comparison of the single-channel properties of synaptic and extrasynaptic NMDA receptors. J Neurosci 17:107-116.

Constantine-Paton M, Cline HT, Debski E (1990) Patterned activity, synaptic convergence, and the NMDA receptor in developing visual pathways. Annu Rev Neurosci 13:129-154.

Crair MC, Malenka RC (1995) A critical period for long-term potentiation at thalamocortical synapses. Nature 375:325-328.

Cull-Candy SG, Leszkiewicz DN (2004) Role of distinct NMDA receptor subtypes at central synapses. Sci STKE 2004:re16.

Das S, Sasaki YF, Rothe T, Premkumar LS, Takasu M, Crandall JE, Dikkes P, Conner DA, Rayudu PV, Cheung W, Chen HS, Lipton SA, Nakanishi N (1998) Increased NMDA current and spine density in mice lacking the NMDA receptor subunit NR3A. Nature 393:377-381.

DeFelipe J, Alonso-Nanclares L, Arellano JI (2002) Microstructure of the neocortex: comparative aspects. J Neurocytol 31:299-316. 
Egger V, Feldmeyer D, Sakmann B (1999) Coincidence detection and changes of synaptic efficacy in spiny stellate neurons in rat barrel cortex. Nat Neurosci 2:1098-1105.

Farrant M, Feldmeyer D, Takahashi T, Cull-Candy SG (1994) NMDAreceptor channel diversity in the developing cerebellum. Nature 368:335-339.

Feldman DE, Nicoll RA, Malenka RC, Isaac JT (1998) Long-term depression at thalamocortical synapses in developing rat somatosensory cortex. Neuron 21:347-357.

Feldmeyer D, Egger V, Lubke J, Sakmann B (1999) Reliable synaptic connections between pairs of excitatory layer 4 neurones within a single "barrel" of developing rat somatosensory cortex. J Physiol (Lond) 521:169-190.

Fleidervish IA, Friedman A, Gutnick MJ (1996) Slow inactivation of $\mathrm{Na}^{+}$ current and slow cumulative spike adaptation in mouse and guinea-pig neocortical neurones in slices. J Physiol (Lond) 493:83-97.

Fleidervish IA, Binshtok AM, Gutnick MJ (1998) Functionally distinct NMDA receptors mediate horizontal connectivity within layer 4 of mouse barrel cortex. Neuron 21:1055-1065.

Gil Z, Amitai Y (1996) Adult thalamocortical transmission involves both NMDA and non-NMDA receptors. J Neurophysiol 76:2547-2554.

Green GM, Gibb AJ (2001) Characterization of the single-channel properties of NMDA receptors in laminae I and II of the dorsal horn of neonatal rat spinal cord. Eur J Neurosci 14:1590-1602.

Hoffmann H, Gremme T, Hatt H, Gottmann K (2000) Synaptic activitydependent developmental regulation of NMDA receptor subunit expression in cultured neocortical neurons. J Neurochem 75:1590-1599.

Huettner JE, Bean BP (1988) Block of N-methyl-D-aspartate-activated current by the anticonvulsant MK-801: selective binding to open channels. Proc Natl Acad Sci USA 85:1307-1311.

Isaacson JS, Murphy GJ (2001) Glutamate-mediated extrasynaptic inhibition: direct coupling of NMDA receptors to $\mathrm{Ca}^{2+}$-activated $\mathrm{K}^{+}$channels. Neuron 31:1027-1034.

Kimura S, Mullins JJ, Bunnemann B, Metzger R, Hilgenfeldt U, Zimmermann F, Jacob H, Fuxe K, Ganten D, Kaling M (1992) High blood pressure in transgenic mice carrying the rat angiotensinogen gene. EMBO J 11:821-827.

Kumar SS, Huguenard JR (2003) Pathway-specific differences in subunit composition of synaptic NMDA receptors on pyramidal neurons in neocortex. J Neurosci 23:10074-10083.

Lin JW, Ju W, Foster K, Lee SH, Ahmadian G, Wyszynski M, Wang YT, Sheng M (2000) Distinct molecular mechanisms and divergent endocytotic pathways of AMPA receptor internalization. Nat Neurosci 3:1282-1290.

McBain CJ, Mayer ML (1994) N-methyl-D-aspartic acid receptor structure and function. Physiol Rev 74:723-760.

Mercer EH, Hoyle GW, Kapur RP, Brinster RL, Palmiter RD (1991) The dopamine beta-hydroxylase gene promoter directs expression of $E$. coli lacZ to sympathetic and other neurons in adult transgenic mice. Neuron 7:703-716.

Misra C, Brickley SG, Wyllie DJ, Cull-Candy SG (2000) Slow deactivation kinetics of NMDA receptors containing NR1 and NR2D subunits in rat cerebellar Purkinje cells. J Physiol (Lond) 525:299-305.

Momiyama A, Feldmeyer D, Cull-Candy SG (1996) Identification of a na- tive low-conductance NMDA channel with reduced sensitivity to $\mathrm{Mg}^{2+}$ in rat central neurones. J Physiol (Lond) 494:479-492.

Monyer H, Sprengel R, Schoepfer R, Herb A, Higuchi M, Lomeli H, Burnashev N, Sakmann B, Seeburg PH (1992) Heteromeric NMDA receptors: molecular and functional distinction of subtypes. Science 256:1217-1221.

Monyer H, Burnashev N, Laurie DJ, Sakmann B, Seeburg PH (1994) Developmental and regional expression in the rat brain and functional properties of four NMDA receptors. Neuron 12:529-540.

Munoz A, Woods TM, Jones EG (1999) Laminar and cellular distribution of AMPA, kainate, and NMDA receptor subunits in monkey sensory-motor cortex. J Comp Neurol 407:472-490.

Nakanishi S (1992) Molecular diversity of glutamate receptors and implications for brain function. Science 258:597-603.

Nevian T, Sakmann B (2004) Single spine $\mathrm{Ca}^{2+}$ signals evoked by coincident EPSPs and backpropagating action potentials in spiny stellate cells of layer 4 in the juvenile rat somatosensory barrel cortex. J Neurosci 24:1689-1699.

Nusser Z, Sieghart W, Somogyi P (1998) Segregation of different GABA receptors to synaptic and extrasynaptic membranes of cerebellar granule cells. J Neurosci 18:1693-1703.

Sah P, Hestrin S, Nicoll RA (1989) Tonic activation of NMDA receptors by ambient glutamate enhances excitability of neurons. Science 246:815818.

Sanchez-Vives MV, McCormick DA (2000) Cellular and network mechanisms of rhythmic recurrent activity in neocortex. Nat Neurosci 3:1027-1034.

Sasaki YF, Rothe T, Premkumar LS, Das S, Cui J, Talantova MV, Wong HK, Gong X, Chan SF, Zhang D, Nakanishi N, Sucher NJ, Lipton SA (2002) Characterization and comparison of the NR3A subunit of the NMDA receptor in recombinant systems and primary cortical neurons. J Neurophysiol 87:2052-2063.

Schubert D, Kotter R, Zilles K, Luhmann HJ, Staiger JF (2003) Cell typespecific circuits of cortical layer IV spiny neurons. J Neurosci 23:2961-2970.

Suchanek B, Seeburg PH, Sprengel R (1997) Tissue specific control regions of the $\mathrm{N}$-methyl-D-aspartate receptor subunit NR2C promoter. Biol Chem 378:929-934.

Sun L, Shipley MT, Lidow MS (2000) Expression of NR1, NR2A-D, and NR3 subunits of the NMDA receptor in the cerebral cortex and olfactory bulb of adult rat. Synapse 35:212-221.

Watanabe M, Inoue Y, Sakimura K, Mishina M (1992) Developmental changes in distribution of NMDA receptor channel subunit mRNAs. NeuroReport 3:1138-1140.

White EL, Rock MP (1980) Three-dimensional aspects and synaptic relationships of a Golgi-impregnated spiny stellate cell reconstructed from serial thin sections. J Neurocytol 9:615-636.

Wyllie DJ, Behe P, Nassar M, Schoepfer R, Colquhoun D (1996) Singlechannel currents from recombinant NMDA NR1a/NR2D receptors expressed in Xenopus oocytes. Proc R Soc Lond B Biol Sci 263:1079-1086.

Zhu JJ, Connors BW (1999) Intrinsic firing patterns and whisker-evoked synaptic responses of neurons in the rat barrel cortex. J Neurophysiol 81:1171-1183. 